\title{
Answer to "Basal ganglia symmetric and asymmetric calcifications can reflect mitochondrial disorders"
}

\author{
Amado Jiménez-Ruiz ${ }^{*}$ and José Luis Ruiz-Sandoval \\ ${ }^{1}$ Internal Medicine; ${ }^{2}$ Department of Neurology. Hospital Civil de Guadalajara. Guadalajara, Jalisco, Mexico
}

We read with attention the letter to the editor sent by Finsterer and Maeztu' about the article "Symmetrical and bilateral basal ganglia calcification. Case series and literature review". ${ }^{2}$

We know that the brain is functionally and structurally asymmetric, even in healthy individuals. ${ }^{3}$ We consider that CT-obtained images can be slightly asymmetric due to different factors, including rotation and inclination at the moment of image acquisition. This can change the way image is appreciated for correct interpretation, in addition to other causes such as lack of patient cooperation (especially in neurology), technicians' lack of skill or computer systems calibration alteration. Some of these factors might influence on the images and give the appearance that they are not $100 \%$ identical; however, they have the same anatomical location in both hemispheres.

The study comprised from late 2012 to early 2016 (four years) and included patients admitted to the internal medicine department for diagnosis and who met basal ganglia symmetric calcification imaging criteria. We do not know the percentage of this radiological finding in that period (2012-2016), since that was not the purpose of the study.

Patients 2 and 3 had no other trait suggestive of mitochondrial disease (family history, hyperlactatemia, other endocrine disorders, heart rate alterations, short stature, etc.). An investigation of cases of MELAS syndrome had been previously carried out in the same center, and thus there was sensitivity towards differential diagnosis. ${ }^{4}$

Unfortunately, molecular diagnosis for mitochondrial cytopathies is not performed in said center, and the cases of MELAS syndrome were diagnosed by signs and symptoms consistent with MELAS, imaging studies and muscle biopsy with the presence of ragged red fibers in Gomori trichrome.

Mitochondrial cytopathies are a group of highly heterogeneous metabolic disorders. Due to the complexity and the diagnostic challenge they represent, in the approach to basal ganglia symmetric calcification, the search for these conditions should be included. ${ }^{5}$

We appreciate the comments.

\section{References}

1. Finsterer J, Maeztu C. Las calcificaciones simétricas y asimétricas de los ganglios basales pueden reflejar enfermedad mitocondrial. Gac Med Mex. 2018;154:501

2. Jiménez-Ruiz A, Cárdenas-Sáenz O, Ruiz-Sandoval JL. Calcificación simétrica y bilateral de ganglios basales. Serie de casos y revisión de la iteratura. Gac Med Mex. 2018;154:258-262.

3. Liu SX. Symmetry and asymmetry analysis and its implications to computer-aided diagnosis: a review of the literature. J Biomed Inform. 2009; 42:1056-1064.

4. Muñoz-Nevárez LA, Martín-Nares E, Ontiveros-Mercado H, Alvarado-Verduzco H, Valerdi-Contreras L, Ramírez-Guzmán MG. MELAS: una serie de casos del Hospital Civil de Guadalajara Fray Antonio Alcalde. Rev Endocrinol Nutr. 2013;21:138-147.

5. Finsterer J. Features on cerebral imaging suggesting mitochondrial disorder. Neurodegener Dis Manag. 2018;8:215-216.
Gac Med Mex. 2019;155:200-200

Contents available at PubMed www.gacetamedicademexico.com 